Article

\title{
The Role of Multiple Injections on Combustion in a Light-Duty PPC Engine
}

\author{
Rickard Solsjö, Mehdi Jangi, Bengt Johansson and Xue-Song Bai * \\ Department of Energy Sciences, Lund University, Box 118, 22100 Lund, Sweden; \\ rickard.solsjo@cd-adapco.com (R.S.); M.Jangi@bham.ac.uk (M.J.); bengt.johansson@kaust.edu.sa (B.J.) \\ * Correspondence: Xue-Song.Bai@energy.lth.se
}

Received: 30 August 2020; Accepted: 19 October 2020; Published: 22 October 2020

\begin{abstract}
This paper presents a numerical investigation of the ignition and combustion process of a primary reference fuel in a partially premixed light-duty internal combustion (PPC) engine. Partially pre-mixed combustion is achieved by employing a multiple injection strategy with three short injection events of fuel pulses. The timing of the first two fuel pulses, 48 and 22 crank angle degrees before top dead center, are chosen with the purpose to stratify the fuel and air charge, whereas the third injection, at five crank angle degrees before top dead center, serves as an actuator of the main heat release. In addition to this baseline injection, three alternative injection strategies are studied, including a split-fuel two-injection strategy and modified triple-injection strategies. Large eddy simulations are employed utilizing a skeletal chemical kinetic mechanism for primary reference fuel capable of capturing the low-temperature ignition and the high temperature combustion. The large eddy simulation (LES) results are compared with experiments in an optical accessible engine. The results indicate that the first ignition sites are in the bowl region where the temperature is relatively higher, and the reaction fronts thereafter propagate in the swirl direction and towards the centerline of the cylinder. The charge from the first two injections initially undergoes low-temperature reactions and thereafter high-temperature reservoirs are formed in the bowl region. The main heat-release is initiated in the engine when the fuel from the third injection reaches the high-temperature reservoirs. Finally, the remaining fuel in the lean mixtures from the first two injections is oxidized. By variation of the injection strategy, two trends are identified: (1) by removing the second injection a higher intake temperature is required to enable the ignition of the charge, and (2) by retarding second injection, a longer ignition delay is identified. Both can be explained by the stratification of fuel and air mixture, and the resulting reactivity in various equivalence ratio and temperature ranges. The LES results reveal the details of the charge stratification and the subsequent heat release process. The present results indicate a rather high sensitivity of partially premixed combustion process to the injection strategies.
\end{abstract}

Keywords: partially premixed combustion; multiple injection strategy; primary reference fuel; low-temperature combustion; internal combustion engines; large eddy simulations

\section{Introduction}

The rapid worldwide growth of the automobile and truck industry intensifies the request of crude oil and globally strains the economic situation on the fuel market [1]. Over the past decades concerns about fuel economy and stringent emission legislation have pushed forward the development of reciprocating combustion engines. Contemporary reduction of soot, NOx, unburned hydrocarbons, and carbon monoxide requires efficient after-treatment solutions as well as in-cylinder solutions, e.g., advanced high-pressure fuel injection strategies, manipulation of engine flow, and optimal piston geometry design. One approach that has shown to potentially cope with the demands is the partially 
premixed combustion (PPC) engine. The PPC concept was first developed for heavy-duty (HD) engine conditions with diesel and gasoline fuel, e.g., [2-4], and has with optimization of various operating conditions, e.g., injection strategies, fuel octane number and exhaust gas recirculation, managed to simultaneously increase the engine efficiencies and to decrease the pollutants [5-11].

The possibility to extend the low-load operation limit for gasoline type fuel in light-duty (LD) PPC engines, i.e., fuel with high octane number $(\mathrm{ON})$, has been the target of recent research. Methods such as re-breathing and exhaust gas retaining techniques and advanced injection strategies to control the onset of combustion have been investigated. Borgqvist et al. [12,13] showed that low amounts of residual trapping are favorable to minimize the gas-exchange loss, but the combustion efficiency is low due to the reduced in-cylinder temperature. Sellnau et al. $[14,15]$ employed a triple injection strategy with fuel octane number of 91 . They showed that at low-load conditions, low levels of soot, and low noise could be obtained, with high level of exhaust re-breathing.

Despite these successful demonstrations of the PPC technique, the fundamental physics of the mixing and combustion processes requires further investigation. It is unclear how the fuel injected at different stages mix and ignites, how the reaction zone structures develop under different PPC conditions, and how the pollutant species are formed under low load conditions. Such detailed knowledge aids the understanding of the performance of PPC engines. This has motivated the present work, in which we employ high fidelity CFD approaches to simulate the detailed mixing and combustion process of an experimental PPC engine.

Three-dimensional numerical investigations on partially premixed combustion have been reported on singe-injection and low temperature combustion [16-18]. Some multi-dimensional CFD work was carried out using KIVA 3 VERC-Chemkin [15]. Most of the work was oriented towards emission-formation and heat-release rate analysis. Previous CFD results showed that with triple-injection, low levels of soot are obtained due to the overall lean conditions and the heat-release rates (HRR) were favorable (with lower peak HRR and longer combustion duration) due to combustion phasing close to top-dead-center (TDC), with low heat losses to the cylinder walls. There is, however, a lack of explanation of the combustion and emission behavior in multiple injection PPC engines. In this regard, numerical simulations and optical engine experiments are needed to explain the sequential ignition and combustion behavior in PPC engines, and how the combustion and pressure-rise rate are affected by the injection strategy.

This paper reports on a numerical investigation on partially premixed combustion in a light-duty compression ignition engine. The aim of the investigation is to improve the understanding of the sequential ignition and combustion process typical of light-duty PPC engines. Large eddy simulation (LES) is employed in this work. The simulations takes into account the spray breakup, evaporation, mixing with the ambient gas, and the subsequent combustion process in a partially premixed combustion engine modified for optical measurement. The injection strategy employs a triple fuel injection with primary reference fuel (PRF) with 69\% iso-octane and 31\% n-heptane (PRF69) in the presence of swirl and low levels of diluted air. The results are utilized to quantify the evolution of the fuel and air mixing, initial low temperature stage ignition, and high-temperature combustion. The impact of the multiple injection event on the charge stratification, and subsequently on the ignition behavior and emissions of $\mathrm{CO}$, unburned hydrocarbons, and NOx, is identified.

\section{Computational Cases and Engine Operation Conditions}

The computation was performed for a five-cylinder VOLVO D5 optical engine. The original VOLVO engine was modified for optical access with a Bowditch design [19]. The piston has a bore of $81 \mathrm{~mm}$ and a stroke of $93.2 \mathrm{~mm}$ with a maximum piston bowl radius of $23.5 \mathrm{~mm}$. The engine was operating at $800 \mathrm{rpm}$ and at approximately 2 bar indicated mean effective pressure (IMEP). Combustion was enabled only in one cylinder, whereas the other 4 cylinders were motored. The compression ratio was set to 11.4:1. An alternating current (AC) dynamometer was used to control the engine speed and load, and an electrical heater in the intake manifold was used to control the inlet temperature. Negative valve overlap (NVO) was used for the control of combustion stability. For the NVO strategy, 
early exhaust valve closing (EVC) and late intake valve opening (IVO) were incorporated in order to retain large quantities of residuals in the cylinder. NVO provided thermal and dilution advantages of residual retaining in the cylinder. Specifically, the NVO was set to $60 \mathrm{CAD}$ (crank angle degrees) and the global equivalence ratio was about 0.30 . The intake temperature was maintained at $80^{\circ} \mathrm{C}$ with the intake pressure at 1.35 bar. A direct injection Bosch common rail system was employed in the engine with a 5-hole nozzle solenoid injector and a $72^{\circ}$ inter-jet angle. The injector had an umbrella angle of $140^{\circ}$ and a nozzle hole diameter of $159 \mu \mathrm{m}$. To generate a partially premixed mixture a triple injection strategy was employed, with the corresponding injection timing at 48, 22, and 5 CAD before TDC, for the first, second, and third injection event, respectively. The injection duration was 2-3 CAD per injection event. The first injection was aimed to form a homogeneous fuel and air baseline charge, the second injection was intended to control the combustion phasing, while the last injection was used as an actuator for the main heat release. Combustion phasing denoted using the crank angle at which $50 \%$ of the total chemical energy in the fuel was released (CA 50) was kept at 5 CAD after TDC. A Kistler6053CC60 piezo-electric pressure transducer was used to measure the in-cylinder pressure. Further details about the engine configuration, piston geometry and experimental apparatus can be found in Refs. [12,13,20].

Borgqvist et al. [12] calculated the effect of NVO on the initial gas composition by using OD AVL Boost numerical simulations. An NVO of $60 \mathrm{CAD}$ corresponded to a $10 \%$ contribution of dilution of burned products to the fresh gas and with a $50^{\circ}$ increase of the in-cylinder temperature charge, which has been considered in the simulations.

\section{Computational Model}

LES of fuel spray combustion in PPC engines provides temporally evolving and three-dimensional information of the temperature and composition in the cylinder. Such instantaneous and local information is important for understanding the physics of the reacting sprays and flow. The PPC engine is intended to operate under fuel-lean and low temperature combustion conditions, using advanced injection strategies and exhaust gas dilution. Under these circumstances, the in-cylinder charge is highly stratified, and the start of combustion is highly sensitive to the instantaneous properties of the gases [21,22]. LES offers the temporal and spatial resolution that can reasonably replicate the multi-mode ignition/flame propagation process in PPC engines [23].

The governing equations for combustion LES are made up of the spatially filtered continuity equation, and transport equations for momentum, enthalpy, and species mass fractions for the gas phase. The chemical reactions in the gas phase and the interaction between the liquid and gas phases were modeled in the source terms of the governing equations, e.g., to account for the heat, mass, and momentum exchange between the phases. The subgrid scale (SGS) terms in the gas phase governing equations were modeled using a one-equation eddy model discussed in Reference [24] and the partially stirred reactor model of Kong and Reitz [25] was used for turbulence/chemistry interaction. The Lagrangian particle tracking (LPT) approach was used for the liquid phase, taking into account of the effects of stochastic dispersion of droplets and spray-induced turbulence [26-28]. The droplets were assumed to have undergone atomization, and further disintegration of droplets was modeled with classical WAVE theory [29] and fuel evaporation was modeled following Crowe et al. [30]. In the simulations, $1 \mathrm{mg}$ of fuel was injected using approximately 70,000 trajectory parcels and the initial droplet size distribution was assumed within the interval 5-159 $\mu \mathrm{m}$, where $159 \mu \mathrm{m}$ was the nozzle hole diameter. An open source CFD code, OpenFoam [31], was used to solve numerically the governing equations. TVD (total variation diminishing) finite volume scheme for compressible flows was employed to discretize the equations and the time integration was performed using a second order implicit method.

In PPC engines the combustion process is initiated by the low-temperature and high-temperature chemistry. Description of the ignition process in a complex stratified charge often requires a relatively detailed chemical kinetic mechanism. A central issue of LES of PPC engine is the integration of large 
chemical kinetic mechanisms with flow transport simulations since the computational cost is often prohibitively expensive. In this work, a multi-dimensional chemistry coordinate mapping (CCM) approach [32-34] was used. In CCM approach, the integration of the chemical reaction rates was performed in phase space, instead of in each computational cell in physical space. The phase space was made up of temperature, mass fraction of $\mathrm{H}$-atom, scalar dissipation rate based on $\mathrm{H}$-atom, and mass fractions of n-heptane. Identical thermochemical cells in physical space were mapped to the phase space, where the integration of the chemical reaction rates was performed. Thereafter, the integrated source terms were mapped back to the computational cells in physical space. The mapping errors were controlled by adjusting the phase-space resolutions and the physical cells with an error greater than the error tolerance was treated separately in the phase-space, to maintain the mapping accuracy. In the present simulation the resolution in the CCM phase space for temperature, mass fraction of $\mathrm{H}$-atom, scalar dissipation rate based on $\mathrm{H}$-atom, and fuel coordinate are $3 \mathrm{~K}, 10^{-4}, 0.1$, and $10^{-3}$, respectively. Details about the method and error analysis can be found in References. [34,35]. The CCM method has previously been used in LES simulations of diesel engine combustion [34,36], in RANS spray simulations [37], and recently integrated with the transport PDF method [38].

The PRF fuel mechanism of Liu et al. [39] is used, with 41 species and 126 reactions, including reactions of very important low-temperature combustion species, e.g., $\mathrm{C} 7 \mathrm{H} 15 \mathrm{O} 2$ and $\mathrm{C} 8 \mathrm{H} 17 \mathrm{O} 2$, as well as high-temperature species, e.g., $\mathrm{OH}$. The mechanism is combined with the extended reactions for NOx formation, including 3 species and 16 steps [40].

The in-cylinder domain is discretized with the finite volume approach and with a layering method stretching in the radial direction, ensuring a fine resolution in the near nozzle region. The sector geometry is shown in Figure 1, as a $72^{\circ}$ part of the full geometry and with a finest mesh resolution of $0.30 \mathrm{~mm}$ and a maximum mesh resolution about $1.2 \mathrm{~mm}$. In the figure, regions I), II), and III) correspond to the target points of the fuel spray injections, respectively for the first, second, and the third injections, which are also labeled as the HCCI, the noise and the diesel injections.

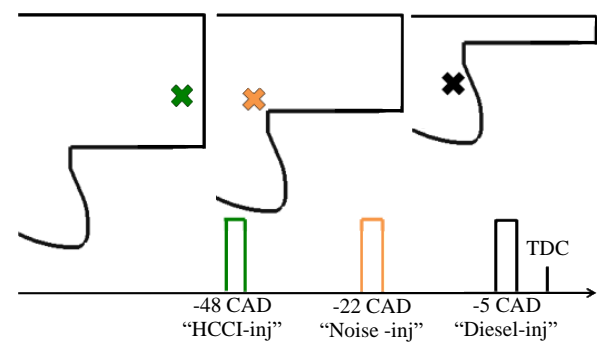

(a)

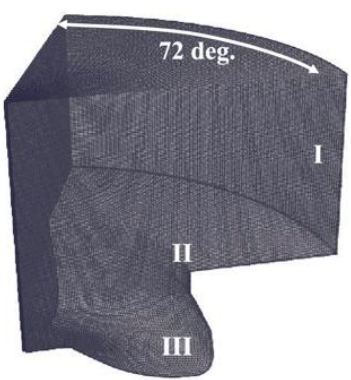

(b)

Figure 1. The triple injection strategy and the target points for case 1 and the experimental work (a) and the simulated sector mesh geometry (b). The spray target points are marked using the cross symbol in the left subfigure, whereas they are labeled as I-III in the right subfigure. Details about the engine configuration and piston geometry can be found in Borgqvist et al. [12,13,20].

The four simulated cases are presented in Table 1 . Case 1 corresponds to the experimental injection strategy and cases $2-4$ are considered to investigate the impact of the injection strategy and temperature on PPC engine combustion process. The total injected fuel to the sector domain (through 1 injector hole) is $1.56 \mathrm{mg}$, which is split into $0.5 \mathrm{mg}$, $0.5 \mathrm{mg}$, and $0.56 \mathrm{mg}$ in the first, second, and third injections for cases 1,2, and 4, respectively. For case 3 the second injection is removed and the fuel for the second injection is split and put to the first and the third injections. 
Table 1. Simulated case. Case 1 corresponds to the experimental case, whereas the cases $2-4$ are performed to investigate the effect of injection strategies on the partially premixed combustion (PPC) engine performance. CAD: crank-angle degree; bTDC: before top-dead-center.

\begin{tabular}{ccccc}
\hline Case & Injection & $\mathbf{1}$ & $\mathbf{2}$ & $\mathbf{3}$ \\
\hline 1 & (CAD bTDC/mg fuel per hole) & $48 / 0.5$ & $22 / 0.5$ & $5 / 0.56$ \\
2 & (CAD bTDC/mg fuel per hole) & $48 / 0.5$ & $17 / 0.5$ & $5 / 0.56$ \\
3 & (CAD bTDC/mg fuel per hole) & $48 / 0.765$ & - & $5 / 0.815$ \\
4 & (CAD bTDC/mg fuel per hole) & $48 / 0.5$ & $27 / 0.5$ & $5 / 0.56$ \\
\hline
\end{tabular}

LES is carried out starting from the bottom dead center (BDC) using dynamic mesh motion algorithm [41] to accommodate the piston motion. The engine flow field at 50 CAD before TDC is stored and used as the initial field for the injection and combustion. A dynamic mesh deformation method with mapping between meshes is employed to ensure low aspect ratio throughout the simulations. The walls are assumed to have constant temperature (liner, $373.15 \mathrm{~K}$, piston, $373.15 \mathrm{~K}$; cylinder head, $373.15 \mathrm{~K}$ ) and as the intake manifold is not considered in the present study, the swirl motion is prescribed at BDC as solid body rotation flow with a swirl number of 2, consistent with the experimental condition.

\section{Results and Discussion}

\subsection{Validation of the LES Model}

The in-cylinder pressure predicted by the LES is in good agreement with the experiments, as shown in Figure 2. In LES, several parameters are unknown due to the use of NVO, e.g., the exact residual gas composition and temperature. Moreover, the quartz piston walls may behave as adiabatic during some parts of the compression stroke and no blow-by model for the piston rings are used. To account for this, the in-cylinder temperature in the LES is adjusted at 25 CAD before TDC (bTDC or -25 CAD after TDC, aTDC) to ensure the ignition delay and combustion phasing to match up with the experiments. Several temperatures were examined and a mean temperature of $930 \mathrm{~K}$ close to TDC was chosen. The effect of the incongruity in pressure during the late compression stroke is believed to have a minor impact on the structure in the PPC combustion process. The total injected fuel mass in the LES was readjusted to compensate for the experimental uncertainties, such as the real delivered fuel mass and fuel losses to, e.g., the crevice volume.

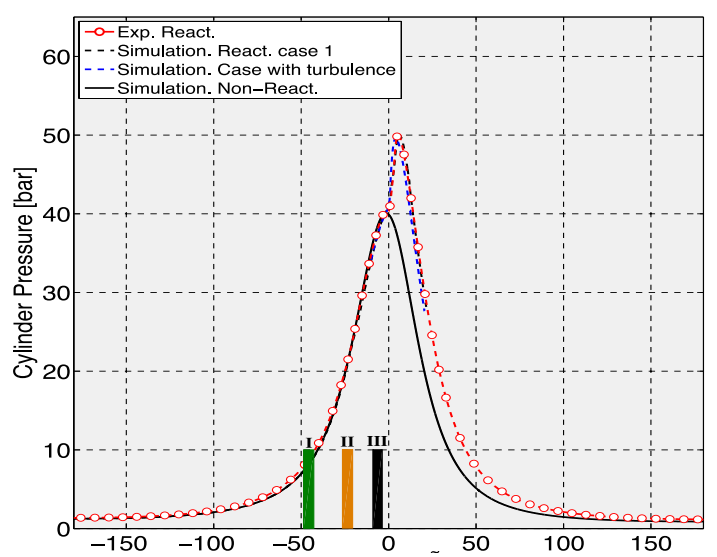

Figure 2. Experimental pressure trace and large eddy simulation (LES) pressure trace, with the first, second, and third injection events, which are indicated as II, II, and III, for the baseline case 1.

The intake valves are not considered in this work and instead the large-scale motions that are generated during the intake procedure are considered by the prescribed solid-body rotation flow. To investigate whether the turbulence fluctuations in the swirling flow play a pivotal role on the fuel and air mixing and combustion process, an initial turbulence field is superimposed to the mean 
swirling flow. The turbulence field is generated using the synthetic turbulent method developed recently [42]. The predicted pressure trace from the reacting case simulations employing the synthetic turbulence field is compared with the pressure trace for the baseline case 1, in Figure 2. In the case of initial turbulence with a root-mean-square of velocity fluctuation of $1.5 \mathrm{~m} / \mathrm{s}$, the intake temperature had to be increased by additionally $20 \mathrm{~K}$ compared with the case with no initial turbulence fluctuations, which corresponds to approximately a $10 \mathrm{~K}$ increase at the intake valve closing. It is seen from Figure 2 and Table 2 that the two pressure-rise rates are comparable, except a slightly higher pressure-rise rate for the case with the initial turbulence taken into account. The required higher initial temperature and the predicted higher pressure-rise rate are owing to that the temperature field and the stratification of the mixture are all relatively more homogeneous when turbulence is stronger. Nevertheless, the main source of turbulence production in the present DI PPC engine is the fuel injections. Considering the unknown turbulence fluctuation in the initial field in the experiments, to simplify the simulations the effect of background turbulence is compensated for by a slight increase of intake temperature in the following sensitivity studies.

Table 2. Indicated mean effective pressure (IMEP) and Peak pressure-rise rate (PRR) of the studied cases. $\mathrm{T}_{0}$ is the temperature of the in-cylinder charge at 25 CAD bTDC.

\begin{tabular}{cccc}
\hline Case & Specification & IMEP [bar] & Peak PRR [bar/CA] \\
\hline 1 & Baseline case & 2.58 & 2.48 \\
1a & Case 1, with initial turbulence & 2.55 & 2.95 \\
2 & Second injection retarded & 2.29 & 1.51 \\
$2 \mathrm{a}$ & Case 2 with 15 K higher T & 2.56 & 2.90 \\
3 & Second injection removed & 1.61 & - \\
3a & Case 3 with 15 K higher T & 2.09 & 0.39 \\
$3 \mathrm{~b}$ & Case 3 with 30 K higher $\mathrm{T}_{0}$ & 2.35 & 1.25 \\
4 & Second injection advanced & 1.33 & 0.14 \\
$4 \mathrm{a}$ & Case 4 with 15 K higher T & 1.35 & 0.45 \\
$4 \mathrm{~b}$ & Case 4 with 30 K higher $\mathrm{T}_{0}$ & 1.44 & 1.36 \\
\hline
\end{tabular}

\subsection{Characteristics of the Partially Premixed Combustion Process}

The stratification of the partially premixed mixture for case 1 under the motored run condition is examined. Figure 3 shows the scatter plot of the computational cells in an equivalence ratio and temperature $(\Phi-T)$ space. The scatter density indicates the probability density (PDF) of finding the cells at the given $\Phi$ and T. The plot is generated at 5 CAD aTDC, which for the baseline case 1 corresponds to the onset of high temperature ignition. Five zones that are identified for the thermaland charge-stratified mixture as labeled (I)-(V). The mixtures correspond respectively to a thermally stratified air charge without fuel in the wall vicinity (region I), a thermally stratified charge with the equivalence ratio between 0.15 and 0.3 in the wall vicinity (region II), a mixture near the wall, and cooled by the engine cylinder-wall (region III), a fuel rich mixture generated in the central part of the engine by the last injection (region IV), and a partially premixed fuel and air mixture generated by the first two injections, at equivalence ratio between 0.15 and 0.35 at around the temperature $800<T<970 \mathrm{~K}$ (region V). From the figure, it is seen that with the current injection strategy there is a high probability to find a region in the engine without any fuel, and most of the charge is in the equivalence ratio range below 0.4 . 


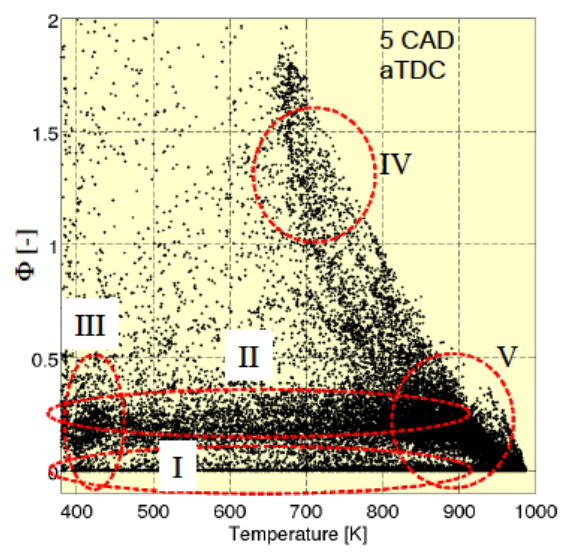

Figure 3. Fuel and air charge stratification in the baseline case 1. Five regions are identified as (I) an air charge without fuel, (II) a thermally stratified charge at constant equivalence ratio, in the wall vicinity, (III) a near wall mixture seen by the low temperature, and (IV) a fuel rich mixture in the central part of the engine from the last injection and $(\mathbf{V})$ a premixed mixture between equivalence ratio 0.15 and 0.35 at around the ambient mean temperature.

To explore the details of the mixing and combustion characteristics for the baseline case 1 , a sequential 2D distribution of key species and temperature in a horizontal plane in the squish volume $8.6 \mathrm{~mm}$ below the cylinder head are displaced in Figure 4. In the figure several important species for low-temperature combustion are shown; the low-temperature species $\mathrm{C}_{7} \mathrm{H}_{15} \mathrm{O}_{2}$, the intermediate temperature species hydro-peroxide $\mathrm{HO}_{2}$ and hydrogen peroxide $\mathrm{H}_{2} \mathrm{O}_{2}$, the high temperature species hydroxyl radicals $\mathrm{OH}$, as well as temperature. The transitions from low temperatures chemical reactions to high temperature reactions can be identified. For some large hydrocarbon fuels, such as the fuel-blend in this case with n-heptane and iso-octane, the negative temperature coefficient (NTC) behavior and two-stage ignition processes are manifested. It is useful to categorize and investigate the importance of the different reactive species, e.g., the species shown in Figure 4, at different pressure and temperature conditions. The chemistry can be divided into different temperature-dependent regimes, e.g., by Westbrook [43],

- Low-temperature chemistry, $\mathrm{T}<850 \mathrm{~K}$

- Mid-temperature chemistry, $850 \mathrm{~K}<\mathrm{T}<1200 \mathrm{~K}$

- High-temperature chemistry, $\mathrm{T}>1200 \mathrm{~K}$

Different elementary reactions are dominant in different regimes. Ignition is related to the chain-branching mechanism that can drive a chemical system to completion in a short period of time and in the PPC engine, the combustion process involves reactions in all of the chemistry regimes.

$\mathrm{C}_{7} \mathrm{H}_{15} \mathrm{O}_{2}$ (denoted as $\mathrm{RO}_{2}$ ), presented in the first column in Figure 4, belongs to the low-temperature regime, where it is difficult to accomplish the radical chain-branching process. $\mathrm{C}_{7} \mathrm{H}_{15} \mathrm{O}_{2}$ is formed by the reaction between an alkyl-radicals $(\mathrm{R})$ and oxygen, $\mathrm{R}+\mathrm{O}_{2}+\mathrm{M}=\mathrm{RO}_{2}+\mathrm{M}$. If the temperature remains below $800 \mathrm{~K}$, the $\mathrm{RO}_{2}$ species can undergo isomerization, in which a hydrogen atom from the heptyl-radical moves and breaks the oxygen bonds, to form $\mathrm{QOOH}$ (where $\mathrm{Q}$ is $\mathrm{C}_{7} \mathrm{H}_{14}$ ). QOOH will react to form ketohydroperoxide (KET) and a radical species hydroxyl $(\mathrm{OH})$. If a cross-over temperature of approximately $800 \mathrm{~K}$ is reached, the KET is decomposed into smaller species and releases at least two radicals and chain branching is achieved. The levels of heat-released in this process may depend on the levels of KETs, and with a higher concentration of KETs, more heat is released. 


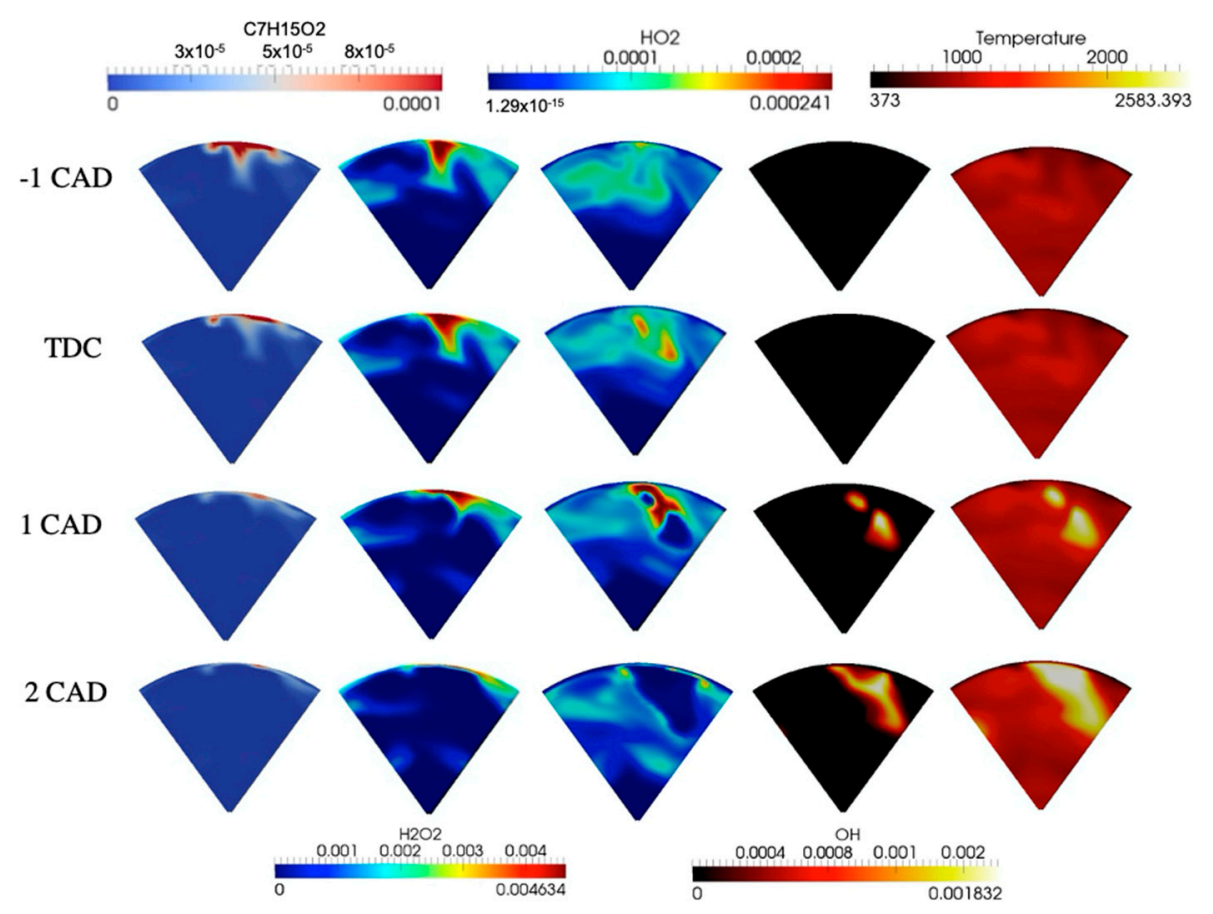

Figure 4. Instantaneous snapshots of mass fractions of (from the left) $\mathrm{RO}_{2}, \mathrm{HO}_{2}, \mathrm{H}_{2} \mathrm{O}_{2}, \mathrm{OH}$, and temperature during an ignition event for the baseline case 1 between -1 CAD and 3 CAD in the horizontal plane $8.6 \mathrm{~mm}$ below the cylinder head.

In the intermediate temperature regime, the important reactions to form more radical species involve thermal decomposition of $\mathrm{H}_{2} \mathrm{O}_{2}$, shown in the second column in Figure 4. $\mathrm{HO}_{2}$ is commonly manifested before the onset of the high temperature ignition, but $\mathrm{H}_{2} \mathrm{O}_{2}$ can start to accumulate at low temperatures; however, the highest concentration of these species is found prior to the onset of ignition. Therefore, $\mathrm{HO}_{2}$ and $\mathrm{H}_{2} \mathrm{O}_{2}$ are considered precursor species for ignition. As the temperature approaches $1000 \mathrm{~K}$, the important reactions between $\mathrm{H}$ radicals and $\mathrm{HO}_{2}$, and an alkane $\mathrm{RH}$ and $\mathrm{H}_{2} \mathrm{O}_{2}$, are

$$
\begin{gathered}
\mathrm{H}+\mathrm{HO}_{2}+\mathrm{M}=\mathrm{HO}_{2}+\mathrm{M} \\
\mathrm{RH}+\mathrm{HO}_{2}=\mathrm{R}+\mathrm{H}_{2} \mathrm{O}_{2} .
\end{gathered}
$$

For the higher temperatures in the intermediate-temperature regime the chain-branching elementary reaction

$$
\mathrm{H}_{2} \mathrm{O}_{2}+\mathrm{M}=\mathrm{OH}+\mathrm{OH}+\mathrm{M},
$$

is important. Low temperature reactions and intermediate temperature reactions are seen to be very important to avoid misfire in PPC combustion engines. As the PPC engines generally operate under low-temperature conditions, the reactions above play an important role in the onset of the main heat-release. In particular, the chain-branching elementary reaction (3) appears to be important. Factors in the system that affect the chemical time scales of $\mathrm{H}_{2} \mathrm{O}_{2}$ would also affect the ignition process. In the high temperature regime, the most important elementary reaction is

$$
\mathrm{H}+\mathrm{O}_{2}=\mathrm{O}+\mathrm{OH}
$$

which is well discussed in the literature and incorporated into most chemical reaction mechanisms. $\mathrm{OH}$ is seen in the fourth column in Figure 4. For a fully homogeneous fuel and air mixture, such as in the HCCI engine, the time period between the first stage and second stage ignition is typically very short and combustion occurs over the entire engine very rapidly. 
It is seen from Figure 4 that the PPC engine combustion behavior is very different from the HCCI engine; the mixture does not homogeneously ignite over the entire cylinder domain. Instead, the start of combustion is initiated at a "preferred" location. The low-temperature species $\mathrm{RO}_{2}$ is formed at the downstream region near the wall. It is quickly consumed due to the high ambient temperature near TDC, around $1000 \mathrm{~K}$, and high levels of hydrogen peroxide are found in a much wide region that the $\mathrm{RO}_{2}$. At $3 \mathrm{CAD}$ aTDC the $\mathrm{RO}_{2}$ vanishes except in the wall boundary layer, where the low temperature inhibits further chemical reactions. Prior to TDC, chemical reactions in the intermediate temperature regimes are manifested by the presence of $\mathrm{HO}_{2}$ and $\mathrm{H}_{2} \mathrm{O}_{2}$. The fuel from the first and second injection has penetrated to the bowl region, either from the squish region by the compressing piston motion, pushing the fuel into the bowl, or by the second injection where a part of the directly injected fuel was oriented into the bowl. This partially premixed fuel mixture corresponds to that of region $\mathrm{V}$ shown in Figure 3. The fuel from the first two injections undergo chemical reactions in such a way that when the last fuel injection is directed into the bowl, the fuel mixes with the hot temperature reservoirs adjacent to the fuel-jet impingement location, which initiate the high-temperature reactions and the main-stage ignition event. If the reservoirs are too cold, it is likely that the cold fuel from the last injection quenches the combustion process. This makes the control of the interactions between the last injection and the two first injections very important for the combustion process.

Furthermore, from Figure 4 it is observed that $\mathrm{HO}_{2}$ and $\mathrm{H}_{2} \mathrm{O}_{2}$ do not co-exist at high mass fraction levels (however note the magnitude difference in the legend) in the same regions. This is consistent with Equation (2) that $\mathrm{HO}_{2}$ reacts to form $\mathrm{H}_{2} \mathrm{O}_{2}$. When ignition occurs, between TDC and $1 \mathrm{CAD}$ in the given cross-section, $\mathrm{H}_{2} \mathrm{O}_{2}$ and $\mathrm{HO}_{2}$ individually have very high local values compared with the surroundings and when they finally are entirely consumed, the high-temperature species $\mathrm{OH}$ appears. As $\mathrm{OH}$ is represented in the high-temperature chemistry regime, $\mathrm{OH}$ is encompassed with a high temperature, shown in column 5 in Figure 4. At TDC it is seen that the first $\mathrm{OH}$ sites correspond to the regions where both $\mathrm{HO}_{2}$ and $\mathrm{H}_{2} \mathrm{O}_{2}$ are consumed. The ignition and the reaction fronts are thereafter propagating towards the fuel impingement region, and also transported in the azimuthal direction, along with the swirl motion.

Figure 5 shows an image sequence of the mixture fraction and mass fractions of $\mathrm{HO}_{2}$ and $\mathrm{OH}$, together with temperature in the vertical plane along the injection axis. The mixture fraction field indicates the fuel distribution. The third injection can be seen at $-2 \mathrm{CAD} . \mathrm{HO}_{2}$ is found near the wall due to the second injection, and by the end of the third injection, $\mathrm{HO}_{2}$ has accumulated in the cross-section following the fuel-jet trajectory in the bowl. In the elapsed time between 0 CAD and 5 CAD, the ignition process has started in the recirculation zones, as describe in Figure 4, and by 5 CAD it has reached the cross-section shown in Figure 5. The high temperature is thereafter found primarily in the piston bowl, spreading from the adjacent hot reservoirs, and propagating into the rest of the domain as the piston expands in the cylinder. Again, the $\mathrm{OH}$ is found in regions where the temperature is high and $\mathrm{HO}_{2}$ has been oxidized.

The combustion event for the entire engine, starting from low-temperature reactions to the high-temperature reactions, is shown in Figure 6 in the $\Phi$-T space. At 10 CAD bTDC mainly the low-temperature chemistry is occurring, below approximately $1000 \mathrm{~K}$ (solid red dots) with some $\mathrm{HO}_{2}$ (bright blue to dark blue color) seen between $800 \mathrm{~K}$ and $1000 \mathrm{~K}$. As the temperature of the cylinder increases by the compressive work from the piston and by the chemical reactions before the start of the last injection at $5 \mathrm{CAD}$ bTDC, $\mathrm{HO}_{2}$ is extended towards the higher temperature regions around equivalence ratio of 0.5 . Around TDC at this equivalence ratio, the first indication of high-temperature reactions appears with $\mathrm{OH}$ (white to black color) as well as elevated levels of ignition chemistry over a range of equivalence ratio owing to the last injection. Between $5 \mathrm{CAD}$ and $10 \mathrm{CAD}$, the main-stage heat release occurs under mainly fuel-lean conditions, around equivalence ratio 0.5 and 1.0 , but also in the slightly fuel-rich mixtures, with the highest mass fraction of $\mathrm{OH}$ at equivalence ratio about 0.8 and temperature $2700 \mathrm{~K}$. The entire main-combustion event under the current conditions is approximately $15 \mathrm{CAD}$, as also seen in the pressure trace in Figure 2. 


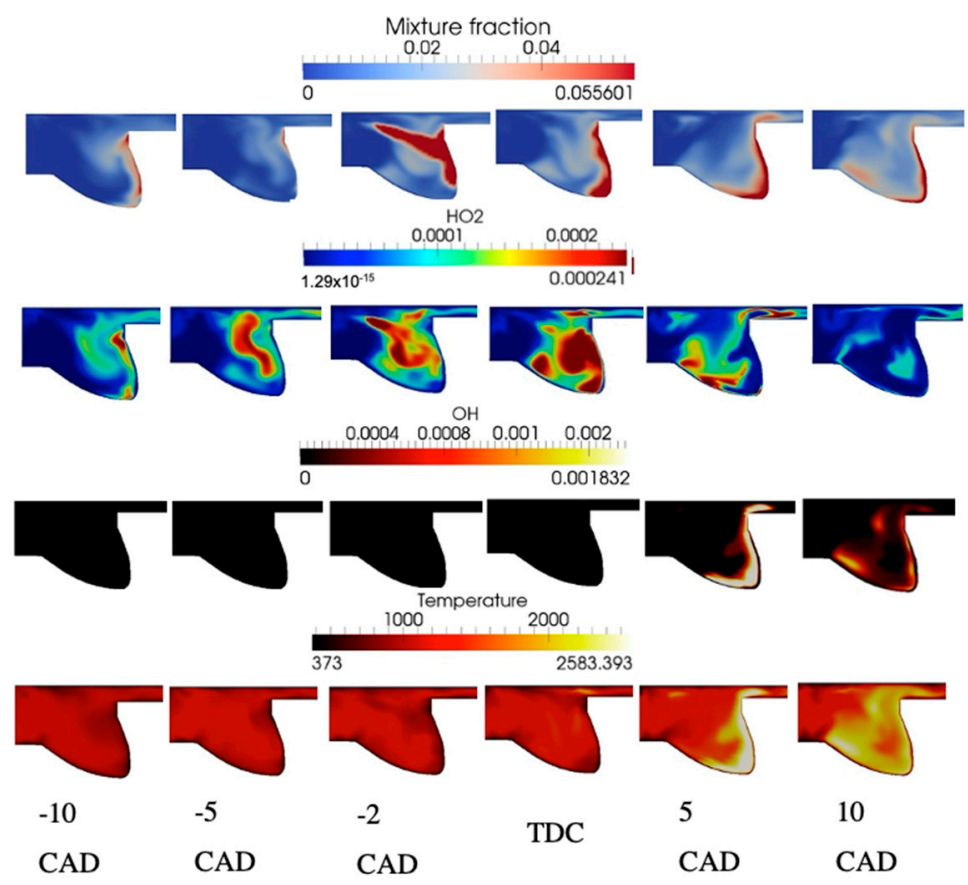

Figure 5. Instantaneous snapshots of the mixture fraction and mass fractions of $\mathrm{HO}_{2}$ and $\mathrm{OH}$, as well as temperature, between $-10 \mathrm{CAD}$ and $15 \mathrm{CAD}$ in the vertical cross section along the injector axis, for the baseline case 1 .
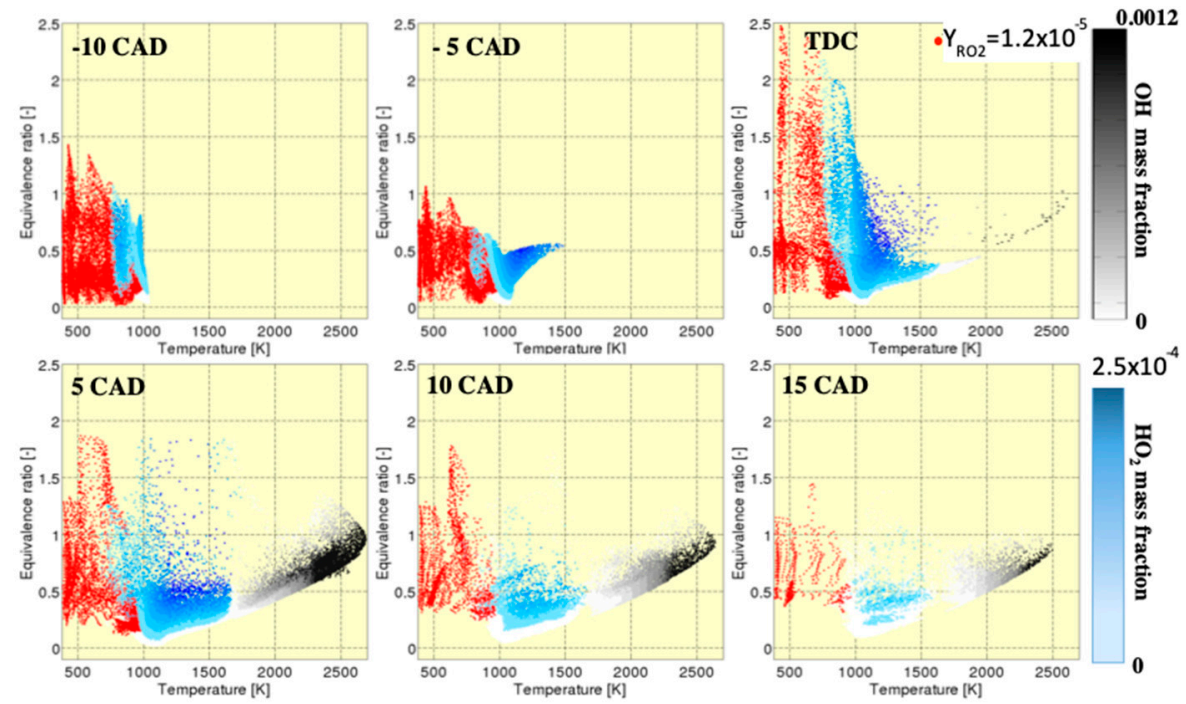

Figure 6. Three species typical for the low, intermediate, and high temperature combustion chemistry regimes plotted in the equivalence ratio and temperature phase space, from -10 to 15 CAD for the baseline case 1 . An active low-temperature chemistry event is indicated by $\mathrm{RO}_{2}$ until $5 \mathrm{CAD}$; thereafter, ignition is initiated at higher temperatures. The main-stage heat-release is found to start between top-dead-center (TDC) and 5 CAD and lasts until 10 CAD to 15 CAD.

Furthermore, scatter plots of the cells in the physical space are presented in Figure 7 in the $\Phi$-T space with the densely scattering region denoting high probability of finding the cells in the given $\Phi$ and T. At -2 CAD, the last injection has occurred, as shown by the fuel rich states in the left box. The first high temperature ignition can be seen in the box to the right. The fuel from the last injection mixes either with the ambient air at 3 CAD, cf. Figure $7 b$, without reacting (region I), or mixes and ignites with the ambient gas (region II). Meanwhile, the fuel and air mixture undergoes ignition around equivalence ratio $0.3-0.4$ or ignites by mixing with the hot combustion gases (region III). At 5 CAD, 
cf. Figure $7 \mathrm{c}$, there are rather rare fuel-rich mixtures seen due to mixing, and the equivalence ratio of the thermochemical states in the high-temperature manifold is decreasing as a result of mixing with the ambient unburned gas, in the direction as indicated by the arrows. At 10 CAD the reaction occurs mainly at $\Phi \sim 0.7$ and below approximately $2000 \mathrm{~K}$. The ignition events shown in Figures 5-7 help explaining the slow pressure-rise rate process that is typical for the PPC combustion engines.
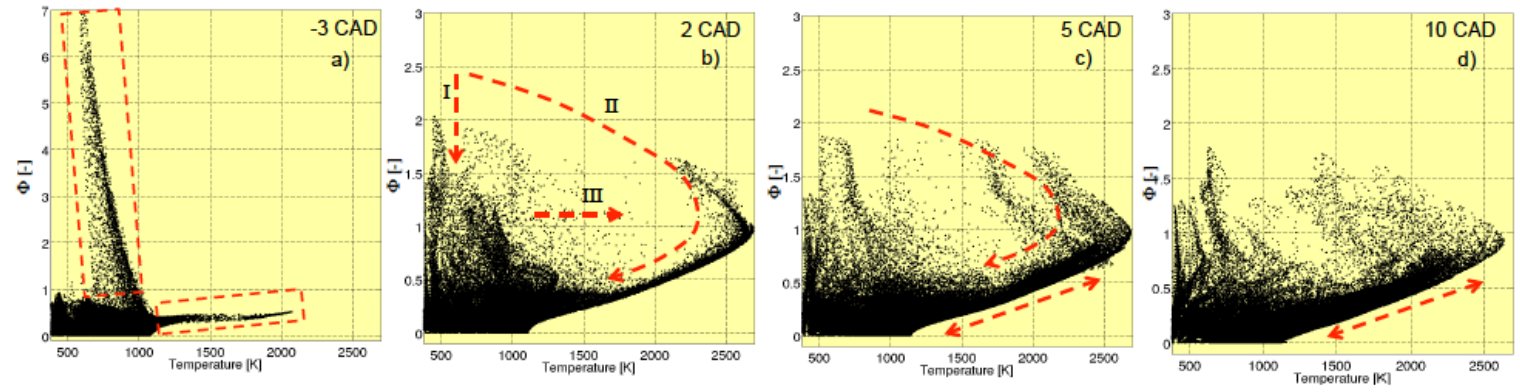

Figure 7. Fuel and air charge stratification from LES for the baseline case 1.

Overall, the sequential combustion event for the light-duty PPC engine is shown to be controlled by the mixing process, between the ambient air and the fuel from the first two injections, and the lowand intermediate temperature reactions of the partially premixed mixture. The mixture undergoes an ignition event in the recirculation zone at a location with a mixture more prone to reactions, adjacent to the fuel jet-wall impingement region of the final injection. The fuel from the last injection is shown to mix with the hot gas and to initiate the main stage ignition event.

\subsection{Sensitivity to the Injection Strategy}

To investigate the sensitivity of the PPC combustion process to the injection strategy three modified injection strategies are considered. The three additional cases, cf. Table 1, are case 2 with postponed second injection timing, case 3 with the second injection fuel mass being divided and put into the first and last injection, and case 4 with the second injection at an earlier timing. The predicted pressure traces for the three cases are compared with the predicted pressure trace for the baseline case 1 , Figure 8. It is seen that the peak pressure of case 2 is lower than that in case 1 unless the intake temperature is increased. In this case, an increase of the initial temperature of $15 \mathrm{~K}$ at $25 \mathrm{CAD}$ bTDC gives a pressure-rise rate closer to that of case 1. For case 3 without any adjustment of the initial temperature the pressure trace shows a poor ignition, nearly a misfire. After increasing the temperature by $15 \mathrm{~K}$, and $30 \mathrm{~K}$, the maximum pressure is still lower than that in case 1 . For case 4 with an earlier second injection, a misfire is predicted even after the initial temperature is increased by $30 \mathrm{~K}$. Due to incomplete combustion, the IMEP (indicated mean effective pressure) are significantly lower in these cases, cf. Table 2.
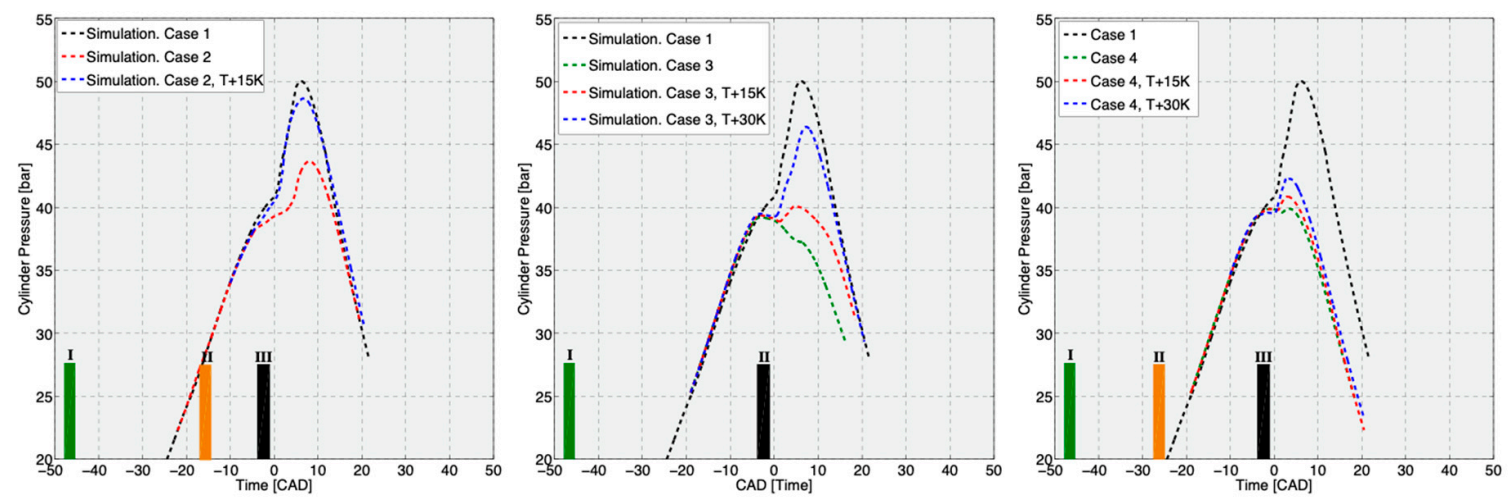

Figure 8. Predicted pressure traces for cases 1-4 at various adjusted initial temperatures. 
As a summary, it appears that the PPC process is very sensitive to the injection strategy. To understand the reason for the predicted behavior for the different injection strategies, an image sequence of the volume-based PDFs of the fuel and air distribution for six different crank angles is shown in Figure 9. At -15 CAD the injection process has just ended for case 2, and it therefore appears as if less fuel is injected. At the same time, the shown CAD is closer to the second injection for case 1 , and thus there is a higher probability of finding fuel-rich mixtures than that for cases 3 and 4 . At $-10 \mathrm{CAD}$, a high probability of finding a mixture with equivalence ratio around 0.2 is shown for cases 3 and 4 . This is attributed to the long mixing time in the case and it is reasonable to believe that the mixture is becoming more homogeneous. Meanwhile, a mixture of higher equivalence ratio is developed for case 2. The reason for this is that the second fuel injection is directed into the piston bowl, and owing to the high jet velocity, the fuel is quickly mixed with the air in the bowl. Contrary to case 2, case 1 exhibits a more stratified mixture, owing to the sequential mixing process: first a relatively rapid mixing between the high speed fuel jets from the first and second injection with the air in the squish volume (because the fuel from the first and the second injections is impinging the upper part of the piston, cf. Figure 1), and then a relatively slower mixing of the mixture in the squish volume with the ambient air in the bowl.
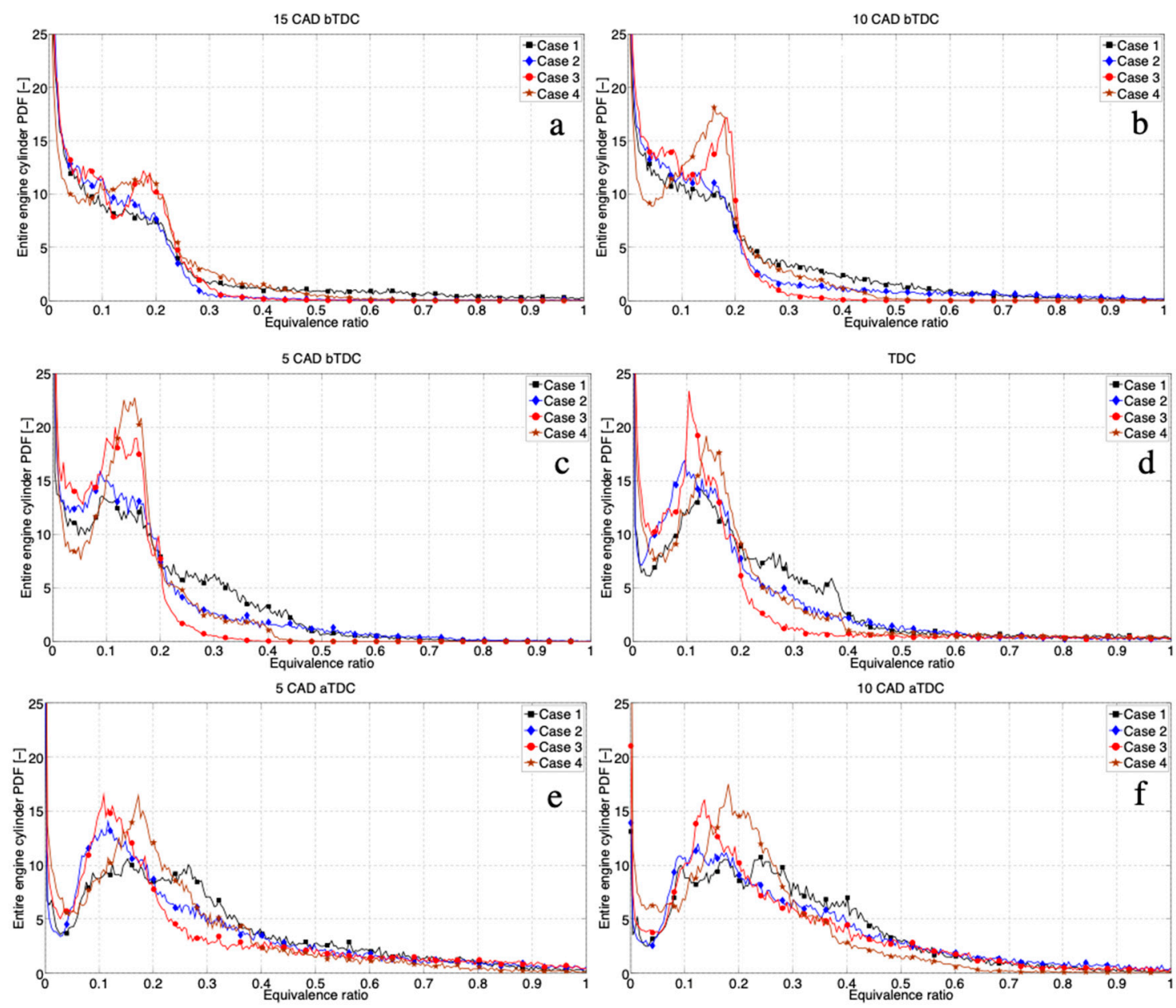

Figure 9. Volume-weighted PDFs for fuel and air mixture distribution as a function of equivalence ratio, for the four cases between -15 CAD and 10 CAD. (a) 15 CAD bTDC; (b) 10 CAD bTDC; (c) 5 CAD bTDC; (d) TDC; (e) 5 CAD aTDC; (f) 10 CAD aTDC.

At -5 CAD, the early injection cases, case 3 and 4, exhibit a very homogeneous mixture around $\Phi=0.1-0.2$. Case 3 has second injection and therefore it lacks the fuel-richer mixtures. Case 1 is found to have a more stratified fuel and air mixture, as compared with the other cases. At this instance and 
until TDC, significant low and intermediate temperature reactions are starting to occur for case 1 , cf. Figure 6. Between $-5 \mathrm{CAD}$ and TDC the third fuel injection is taking place and richer mixtures are obtained for all cases, and between $5 \mathrm{CAD}$ and $10 \mathrm{CAD}$ the main-stage heat release is occurring for cases 1-3.

The fuel from the first injection in case 3 and the first and second injection for case 2 are directed to the squish volume, cf. Figure 1 . Therefore, it is seen that a less stratified fuel and mixture distribution is obtained with early fuel injections for the current engine geometry. The fuel from the second injection in case 2 is directed to the bowl and thus two separated fuel lean regions are predicted in the cylinder. As discussed earlier, the main difference between these cases and the baseline case 1 is that the second injection for case 1 is directed to the squish volume such that it mixes with the fuel from the first injection, and then to the bowl region following the relative low speed flow. This strategy gives a globally more stratified mixture than the other cases.

The effect of the fuel injection strategy on the heat-release rate (HRR) is plotted in Figure 10, for mixtures at various ranges of equivalence ratio. In Figure 11 the corresponding mass of the fuel in the various ranges of equivalence ratio is shown. The heat-release rate is calculated for the fuel mass inside a certain $\Phi$-range, normalized with the total energy that is delivered by the fuel mass within the $\Phi$-range. The delivered fuel energy is calculated by multiplying the fuel mass with the fuel heating value. The heating value for the PRF69 fuel is approximately $44.83 \mathrm{MJ} / \mathrm{kg}$ and the total injected fuel is $1.56 \mathrm{mg}$. This yields approximately a total of $70 \mathrm{~J}$ energy input. Note that the unit for the $y$-axis in Figure 10 is in $1 / \mathrm{s}$.

It is seen that HRR for the mixtures within $0<\Phi<0.2$ is rather low (as compared with the other mixtures, cf. Figure $10 a, b)$ and it is seen that almost $50 \%$ of the fuel mixtures are within this range for all cases. Between the four cases, case 1 exhibits the lowest percentage of fuel mass in this range. The highest HRR is found for cases 3 and 4, which have high amounts of fuel in this region. Owing to the last fuel injection, the contribution of the heat-release in this mixture range is lower after $-5 \mathrm{CAD}$, as the percentage of fuel in this interval is lower. Overall, the reactiveness of the fuel in this interval is lower, and thus it does not contribute significantly to the global heat release in all cases.

Shown in Figure 10b or Figure 11b are the HRR and fuel mass in the interval $0.2<\Phi<0.7$. This is the mixture containing the second largest amount of fuel. Around TDC, case 1 has the highest amount of fuel within the given $\Phi$-range. Significant HRR before TDC is only found in case 1 and case 2 . Case 3 exhibits an abrupt HRR starting around 2 CAD aTDC, thereafter the heat release reaches similar values as for case 1 and 2. Since the fuel mass of case 3 is lowest in this range of equivalence ratio, the overall contribution of the mixture in this range to the total heat release rate is low, which explains the difficulty of ignition of case 3 as shown earlier. For case 4 both HRR and the fuel mass are rather low in this range of equivalence, which explain the reason of misfire for case 4.

Figure 10c or Figure 11c show the HRR and fuel mass in the range of equivalence ratio $0.7<\Phi<1.2$. Compared with the baseline case 1, case 2 with a later second injection results in higher amount of fuel-rich mixture in the later stage (later than TDC), and as such a higher HRR around TDC. Since the fuel mass in this equivalence ratio range is significantly lower than that in the fuel-lean mixtures the overall contribution of the fuel mass in this fuel-richer mixture to total heat release and pressure-rise rate is low. As expected, case 3 without the second injection yields the highest amount fuel mass in the $0.7<\Phi<1.2$ range, which gives rise to the highest HRR among all cases in the equivalence ratio range. Similar to case 2, the fuel mass for case 3 in the equivalence ratio range of $0.7<\Phi<1.2$ is so low that its contribution to the total HRR is low. Case 4 with an earlier second injection shows the opposite behavior to case 2, with lower fuel mass and lower HRR in the equivalence ratio range of $0.7<\Phi<1.2$. 

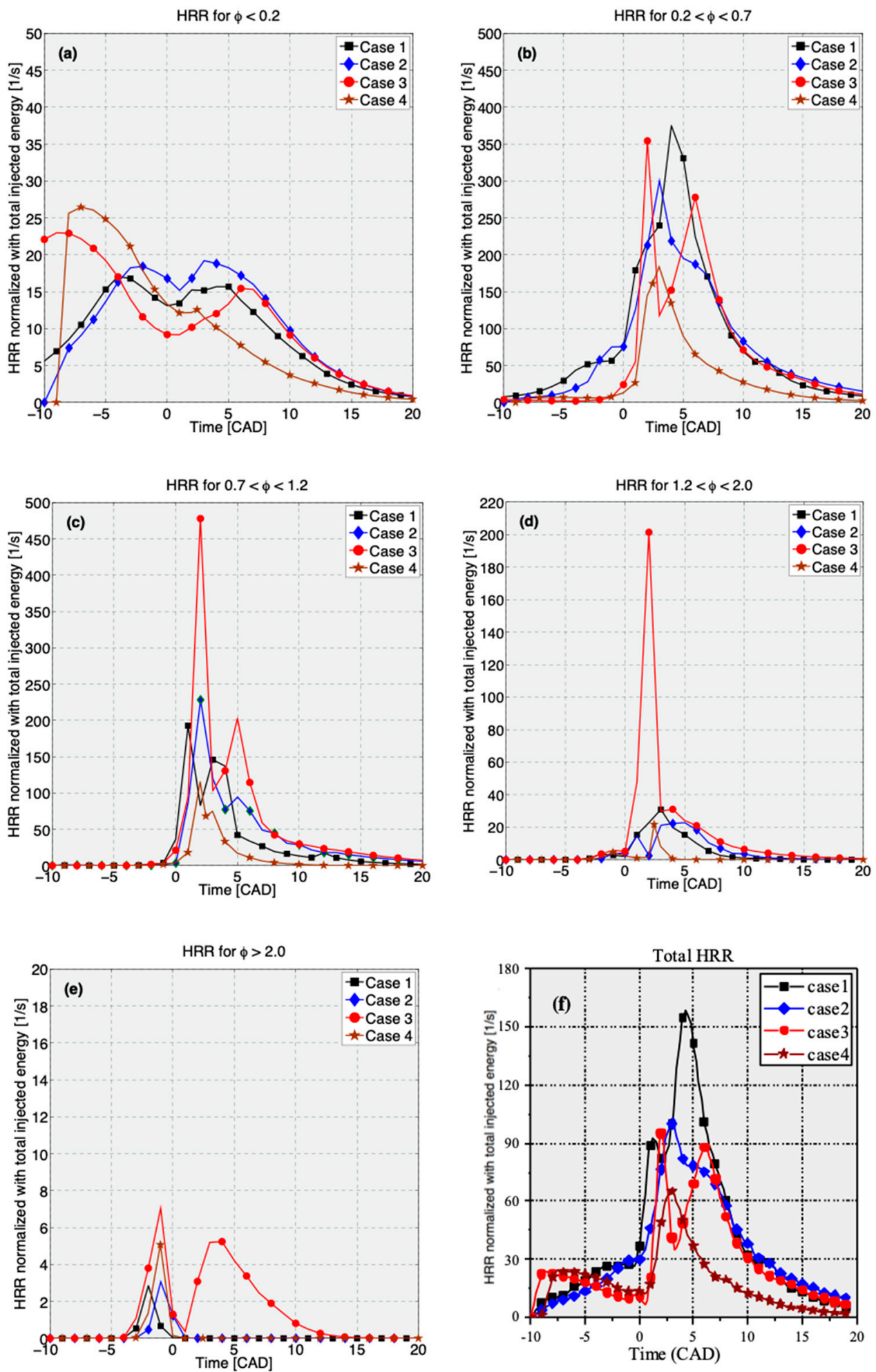

Figure 10. Normalized heat-release rate from the mixtures at various ranges of equivalence ratio (a-e) and total heat-release rates (HRR) from all equivalence ratios (f). The HRR is normalized with the total energy input of the fuel within the respective $\Phi$-range. The adjusted initial temperatures are case 2: $15 \mathrm{~K}$; case 3: $30 \mathrm{~K}$; case 4: $30 \mathrm{~K}$. 

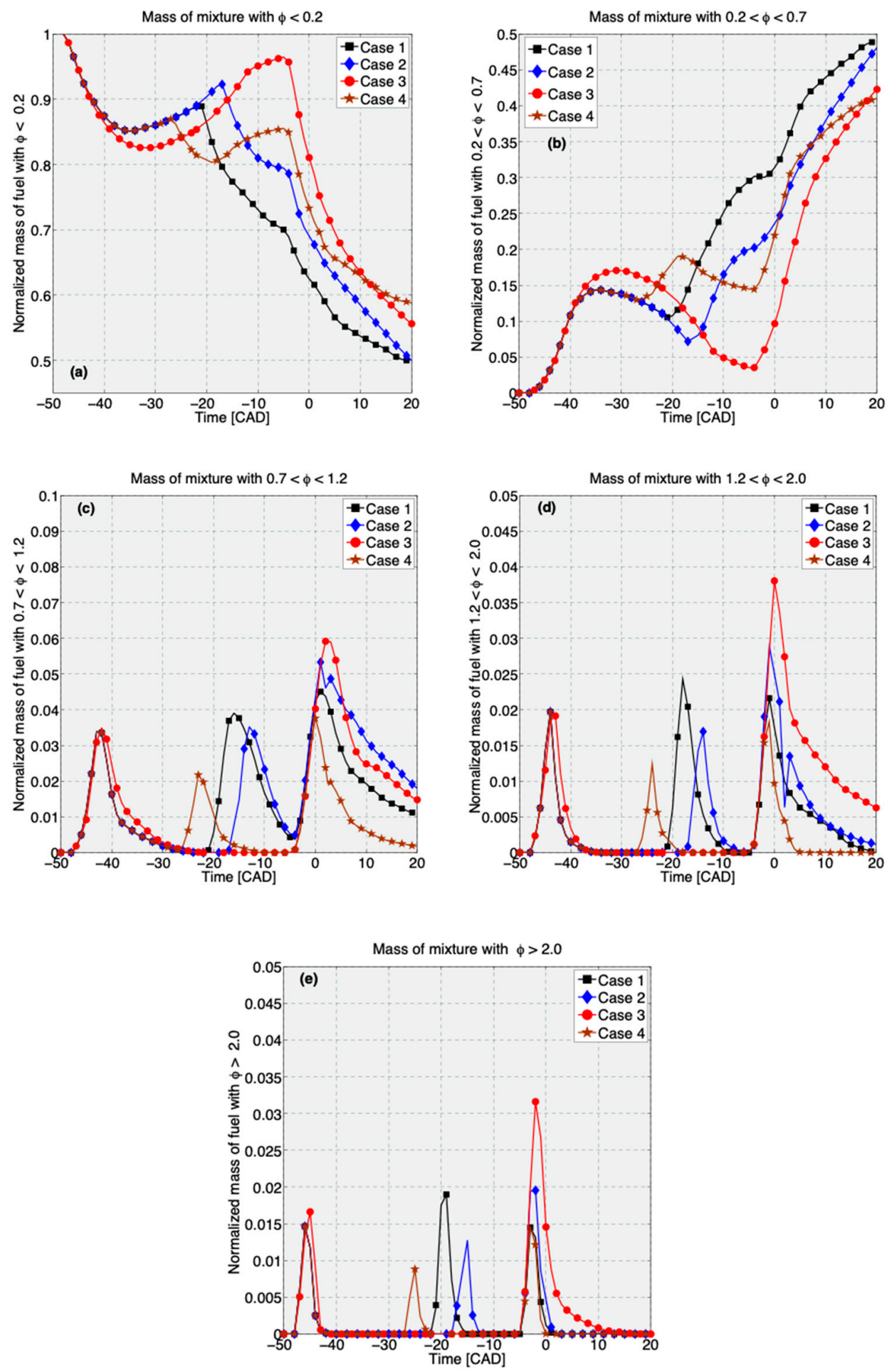

Figure 11. Normalized mass of fuel from the mixtures at various ranges of equivalence ratio. The fuel mass is normalized with the total fuel mass injected to the cylinder, i.e., $1.56 \mathrm{mg}$. The adjusted initial temperatures are case 2: $15 \mathrm{~K}$; case $3: 30 \mathrm{~K}$; case 4: $30 \mathrm{~K}$. (a) $\phi<0.2$; (b) $0.2<\phi<0.7$; (c) $0.7<\phi<1.2$; (d) $1.2<\phi<2 ;(\mathbf{e}) \phi>2$.

For the equivalence ranges $\Phi>1.2$ the behavior is similar to that of $0.7<\Phi<1.2$. The above analysis indicates two important factors affecting the fuel/air mixing and HRR:

- the injection timing;

- the injection direction and piston bowl position. 
It is clear that if the fuel injection is early, e.g., case 4, there will be longer mixing time and more fuel mass in the fuel-lean mixtures. If the fuel is injected later, e.g., case 2, the fuel injection is directed to the bowl and much faster mixing of fuel and air will occur, resulting also a larger amount of fuel in the fuel-lean mixture.

\section{Conclusions}

LES is carried out to investigate the mixing and combustion process of PRF69 fuel in a light duty experimental engine. The simulations are based on LPT coupling of spray and the gas phase. A skeletal chemical kinetic mechanism is considered with a computationally efficient method, the chemistry coordinate mapping method. The LES model is validated by comparing with engine pressure trace obtained from experiments. Due to the lack of experimental data for the flow field there are uncertainties in the initial conditions, e.g., initial turbulence and initial temperature. The sensitivity of LES results to the initial turbulence and initial temperature are investigated. It is shown that satisfactory agreement with the experimental pressure trace can be achieved for different initial turbulence field by adjusting the initial temperature field. This allows us to further investigate the sensitivity of the PPC engine combustion process to injection strategies. Based on the LES results the following concluding remarks are given:

- Depending on the equivalence ratio the stratified mixtures behave differently. Fuel-lean mixtures $(\Phi<0.2)$ ignite earlier but their overall heat release is low. The main effect of fuel-lean mixtures is to assist the ignition of the fuel-richer mixtures. Mixtures in the equivalence ratio range of $0.2<\Phi<0.7$ have the highest heat release rate. In the present PPC engine most of the fuel lies in these mixtures; thus, optimization of the engine performance is largely depending on the mixtures in the equivalence ratio range of $0.2<\Phi<0.7$. The mixtures in the equivalence ratio range of $0.7<\Phi<1.2$ give also high heat release rate but they also give rise to high $\mathrm{CO}$ and $\mathrm{NO}$ emissions. Mixtures in the equivalence ratio range of $\Phi>1.2$ gives rise to the emissions of unburned fuel, $\mathrm{CO}$, and soot.

- The performance of PPC engines is very sensitive to the injection strategies. Multiple injection of fuel generates stratified fuel/air mixture. Too earlier injection would result in a fuel-lean mixture, e.g., in the equivalence ratio range of $\Phi<0.2$; higher initial temperature is required to ignite such mixture and the pressure-rise rate will be high, similar to that in HCCI engines. Too later ignition would result in fuel-rich mixtures similar to diesel engines.

- The performance of PPC engines is also sensitive to the orientation of the injection. The injected fuel stream interacts with the piston bowl. If the fuel is injected directly to the bowl the mixing would be fast and fuel-lean mixtures would be generated. In the present study it is seen that too late second injection would yield a direct injection of the fuel to the bowl.

Author Contributions: Conceptualization, R.S., M.J., B.J. and X.-S.B.; Formal analysis, R.S. and X.-S.B.; Funding acquisition, X.-S.B.; Investigation, R.S.; Methodology, R.S. and M.J.; Software, R.S. and M.J. All authors have read and agreed to the published version of the manuscript.

Funding: This research was funded by Swedish Energy Agency (STEM) through KCFP Center at Lund University.

Acknowledgments: This work was supported by the Competence Center for Combustion Progress (KCFP) and the National Swedish Research Council (VR) and the Swedish Energy Agency. The simulations were performed using Lunarc, the center for scientific and technical computing at Lund University and PDC, center for high performance computing funded by the Swedish National Infrastructure for Computing (SNIC). We thank Leilei Xu for his assistance in the revision of this paper.

Conflicts of Interest: The authors declare no conflict of interest. 


\section{References}

1. Reitz, R.D. Directions in IC engines research. Combust. Flame 2013, 160, 1-8. [CrossRef]

2. Noehre, C.; Andersson, M.; Johansson, B.; Hultqvist, A. Characterization of Partially Premixed Combustion. SAE Tech. Paper Ser. 2006. [CrossRef]

3. Kalghatgi, G.T.; Risberg, P.; Ångström, H.-E. Advantages of Fuels with High Resistance to Auto-ignition in Late-injection, Low-temperature, Compression Ignition Combustion. SAE Tech. Pap. Ser. 2006. [CrossRef]

4. Manente, V.; Johansson, B.; Tunestal, P.; Cannella, W. Effects of Different Type of Gasoline Fuels on Heavy Duty Partially Premixed Combustion. SAE Int. J. Engines 2009, 2, 71-88. [CrossRef]

5. Li, C.; Yin, L.; Shamun, S.; Tuner, M.; Johansson, B.; Solsjo, R.; Bai, X.-S. Transition from HCCI to PPC: The Sensitivity of Combustion Phasing to the Intake Temperature and the Injection Timing with and without EGR. SAE Tech. Pap. Ser. 2016, 1. [CrossRef]

6. Belgiorno, G.; Dimitrakopoulos, N.; Di Blasio, G.; Beatrice, C.; Tuner, M.; Tunestal, P. Parametric Analysis of the Effect of Pilot Quantity, Combustion Phasing and EGR on Efficiencies of a Gasoline PPC Light-Duty Engine. SAE Tech. Pap. Ser. 2017, 1. [CrossRef]

7. Belgiorno, G.; Dimitrakopoulos, N.; Di Blasio, G.; Beatrice, C.; Tunestål, P.; Tunér, M. Effect of the engine calibration parameters on gasoline partially premixed combustion performance and emissions compared to conventional diesel combustion in a light-duty Euro 6 engine. Appl. Energy 2018, 228, 2221-2234. [CrossRef]

8. Sellnau, M.; Foster, M.; Moore, W.; Sinnamon, J.; Hoyer, K.; Klemm, W. Pathway to 50\% Brake Thermal Efficiency Using Gasoline Direct Injection Compression Ignition. SAE Tech. Pap. Ser. 2019, 1, 1581-1603. [CrossRef]

9. Cho, K.; Zhao, L.; Ameen, M.; Zhang, Y.; Pei, Y.; Moore, W.; Sellnau, M. Understanding Fuel Stratification Effects on Partially Premixed Compression Ignition (PPCI) Combustion and Emissions Behaviors. SAE Tech. Pap. Ser. 2019. [CrossRef]

10. Xu, L.; Bai, X.-S.; Li, C.; Tunestål, P.; Tunér, M.; Lu, X. Combustion characteristics of gasoline DICI engine in the transition from HCCI to PPC: Experiment and numerical analysis. Energy 2019, 185, 922-937. [CrossRef]

11. Xu, L.; Bai, X.-S.; Li, C.; Tunestål, P.; Tunér, M.; Lu, X. Emission characteristics and engine performance of gasoline DICI engine in the transition from HCCI to PPC. Fuel 2019, 254, 115619. [CrossRef]

12. Borgqvist, P.; Tuner, M.; Mello, A.; Tunestal, P.; Johansson, B. The Usefulness of Negative Valve Overlap for Gasoline Partially Premixed Combustion, PPC. SAE Tech. Pap. Ser. 2012. [CrossRef]

13. Borgqvist, P.; Andersson, O.; Tunestal, P.; Johansson, B. The Low Load Limit of Gasoline Partially Premixed Combustion Using Negative Valve Overlap. J. Eng. Gas Turbines Power 2013, 135, 062002. [CrossRef]

14. Sellnau, M.C.; Sinnamon, J.; Hoyer, K.; Husted, H. Full-Time Gasoline Direct-Injection Compression Ignition (GDCI) for High Efficiency and Low NOx and PM. SAE Int. J. Engines 2012, 5, 300-314. [CrossRef]

15. Sellnau, M.C.; Sinnamon, J.; Hoyer, K.; Kim, J.; Cavotta, M.; Husted, H. Part-Load Operation of Gasoline Direct-Injection Compression Ignition (GDCI) Engine. SAE Tech. Pap. Ser. 2013. [CrossRef]

16. Dempsey, A.B.; Wang, B.-L.; Reitz, R.D.; Petersen, B.; Sahoo, D.; Miles, P.C. Comparison of Quantitative In-Cylinder Equivalence Ratio Measurements with CFD Predictions for a Light Duty Low Temperature Combustion Diesel Engine. SAE Int. J. Engines 2012, 5, 162-184. [CrossRef]

17. Petersen, B.; Miles, P.C.; Sahoo, D. Equivalence Ratio Distributions in a Light-Duty Diesel Engine Operating under Partially Premixed Conditions. SAE Int. J. Engines 2012, 5, 526-537. [CrossRef]

18. Musculus, M.P.; Miles, P.C.; Pickett, L.M. Conceptual models for partially premixed low-temperature diesel combustion. Prog. Energy Combust. Sci. 2013, 39, 246-283. [CrossRef]

19. Bowditch, F.W. A New Tool for Combustion Research A Quartz Piston Engine. SAE Tech. Pap. Ser. 1961, 610002. [CrossRef]

20. Borgqvist, P.; Tunestal, P.; Johansson, B. Gasoline Partially Premixed Combustion in a Light Duty Engine at Low Load and Idle Operating Conditions. SAE Tech. Pap. Ser. 2012. [CrossRef]

21. Zhang, F.; Yu, R.; Bai, X.S. Direct numerical simulation of PRF70/air partially premixed combustion under IC engine conditions. Proc. Combust. Inst. 2015, 35, 2975-2982. [CrossRef]

22. Zhang, F.; Yu, R.; Bai, X.S. Effect of split fuel injection on heat release and pollutant emissions in partially premixed combustion of PRF70/air/EGR mixtures. Appl. Energy 2015, 149, 283-296. [CrossRef] 
23. Ibron, C.; Fatehi, H.; Wang, Z.; Stamatoglou, P.; Lundgren, M.; Alden, M.; Richter, M.; Anderssona, O.; Bai, X.S. A Numerical simulation of a mixed-mode reaction front in a PPC engine. Ph.D. Thesis, Lund University, Lund, Sweden, 2019.

24. Rutland, C.J. Large-eddy simulations for internal combustion engines-A review. Int. J. Engine Res. 2011, 12, 421-451. [CrossRef]

25. Kong, S.-C.; Reitz, R. Numerical study of premixed HCCI engine combustion and its sensitivity to computational mesh and model uncertainties. Combust. Theory Model. 2003, 7, 417-433. [CrossRef]

26. Bharadwaj, N.; Rutland, C.J.; Chang, S. Large eddy simulation modelling of spray-induced turbulence effects. Int. J. Engine Res. 2009, 10, 97-119. [CrossRef]

27. Menon, S. Subgrid combustion modelling for large-eddy simulations. Int. J. Engine Res. 2000, 1, $209-227$. [CrossRef]

28. Jangi, M.; Solsjo, R.; Johansson, B.; Bai, X.-S. On large eddy simulation of diesel spray for internal combustion engines. Int. J. Heat Fluid Flow 2015, 53, 68-80. [CrossRef]

29. Jiang, X.; Siamas, G.; Jagus, K.; Karayiannis, T. Physical modelling and advanced simulations of gas-liquid two-phase jet flows in atomization and sprays. Prog. Energy Combust. Sci. 2010, 36, 131-167. [CrossRef]

30. Crowe, C.T.; Schwarzkopf, J.D.; Sommerfeld, M.; Tsuji, Y. Multiphase Flows with Droplets and Particles; CRC Press: Boca Raton, FL, USA, 2011.

31. The Open Source CFD Toolbox OpenFoam. Available online: http://www.openfoam.com (accessed on 20 October 2020).

32. Jangi, M.; Bai, X.-S. Multidimensional chemistry coordinate mapping approach for combustion modelling with finite-rate chemistry. Combust. Theory Model. 2012, 16, 1109-1132. [CrossRef]

33. Jangi, M.; Yu, R.; Bai, X.-S. Development of Chemistry Coordinate Mapping Approach for Turbulent Partially Premixed Combustion. Flow Turbul. Combust. 2012, 90, 285-299. [CrossRef]

34. Jangi, M.; Yu, R.; Bai, X.-S. A multi-zone chemistry mapping approach for direct numerical simulation of auto-ignition and flame propagation in a constant volume enclosure. Combust. Theory Model. 2011, 16, 221-249. [CrossRef]

35. Gong, C.; Jangi, M.; Bai, X.-S. Large eddy simulation of n-Dodecane spray combustion in a high pressure combustion vessel. Appl. Energy 2014, 136, 373-381. [CrossRef]

36. Solsjö, R.; Jangi, M.; Chartier, C.; Andersson, O.; Bai, X.-S. Lift-off and stabilization of n-heptane combustion in a diesel engine with a multiple-nozzle injection. Proc. Combust. Inst. 2013, 34, 3031-3038. [CrossRef]

37. Jangi, M.; Lucchini, T.; D'Errico, G.; Bai, X.-S. Effects of EGR on the structure and emissions of diesel combustion. Proc. Combust. Inst. 2013, 34, 3091-3098. [CrossRef]

38. Jangi, M.; Zhao, X.; Haworth, D.C.; Bai, X.-S. Stabilization and liftoff length of a non-premixed methane/air jet flame discharging into a high-temperature environment: An accelerated transported PDF method. Combust. Flame 2015, 162, 408-419. [CrossRef]

39. Liu, Y.D.; Jia, M.; Xie, M.Z.; Pang, B. Enhancement on a skeletal kinetic model for primary reference fuel oxidation by using a semi-decoupling methodology. Energy Fuels 2012, 26, 7069-7083. [CrossRef]

40. Kong, S.-C.; Sun, Y.; Rietz, R.D. Modeling Diesel Spray Flame Liftoff, Sooting Tendency, and NOx Emissions Using Detailed Chemistry with Phenomenological Soot Model. J. Eng. Gas Turbines Power 2005, 129, $245-251$. [CrossRef]

41. Jasak, H.; Tukovic, Z. Automatic mesh motion for the unstructured finite volume method. Trans. FAMENA 2007, 30, 1-20.

42. Yu, R.; Bai, X.-S. A fully divergence-free method for generation of inhomogeneous and anisotropic turbulence with large spatial variation. J. Comput. Phys. 2014, 256, 234-253. [CrossRef]

43. Westbrook, C.K. Chemical kinetics of hydrocarbon ignition in practical combustion systems. Proc. Combust. Inst. 2000, 28, 1563-1577. [CrossRef]

Publisher's Note: MDPI stays neutral with regard to jurisdictional claims in published maps and institutional affiliations. 